\title{
BMJ Open Biological and steroid use in relationship to quality measures in older patients with inflammatory bowel disease: a US Medicare cohort study
}

\author{
Sophia L Johnson, ${ }^{1}$ Christie M Bartels, ${ }^{2}$ Mari Palta, ${ }^{3,4}$ Carolyn T Thorpe, ${ }^{5,6}$ \\ Jennifer M Weiss, ${ }^{7}$ Maureen A Smith ${ }^{3,8,9}$
}

To cite: Johnson SL, Bartels CM, Palta M, et al. Biological and steroid use in relationship to quality measures in older patients with inflammatory bowel disease: a US Medicare cohort study. BMJ Open 2015;5:e008597.

doi:10.1136/bmjopen-2015008597

- Prepublication history and additional material is available. To view please visit the journal (http://dx.doi.org/ 10.1136/bmjopen-2015008597).

Received 27 April 2015 Revised 24 July 2015 Accepted 18 August 2015

CrossMark

For numbered affiliations see end of article.

Correspondence to Dr Sophia L Johnson; sjohnson@rx.umaryland.edu

\section{ABSTRACT}

Objectives: To examine the frequency and predictors of antitumour necrosis factor (TNF) use, and to describe steroid utilisation among US patients with inflammatory bowel disease (IBD) aged 65 years and older prior to the publication of a new Medicare quality measure calling for the use of anti-TNFs and other steroid-sparing agents.

Design: Retrospective cohort study.

Setting: This study utilised 2006-2009 claims data for a national sample of Medicare beneficiaries.

Participants: Patients with IBD (>1 claim for ICD codes 555.xx, 556.xx) without anti-TNF contraindications, enrolled in Medicare parts $A$ and $B$ $\geq 12$ months and part $D \geq 6$ months were included $(\mathrm{n}=8502)$.

Outcome measures: We estimated incidence rate ratios (IRR) and $95 \%$ Cls predicting new anti-TNF therapy using multivariable Poisson regression.

Results: This nationally representative study of older patients with IBD estimated that only $3.7 \%$ received anti-TNFs. New anti-TNF use (1.4\%) was associated with younger age, absence of Medicaid coverage, hospitalisation, and higher preceding use of burst (IRR=2.35, Cl 1.59 to 3.47) and maintenance steroids (IRR=2.40, $\mathrm{Cl} 1.05$ to 5.48). Among anti-TNF users, we observed high rates of concurrent maintenance steroid use (19\%).

Conclusions: Anti-TNF use was very low in this population of older patients with IBD and, importantly, was often combined with maintenance steroid use despite guidelines suggesting reduced needs. Expanding IBD-specific quality measures to include steroid taper plans may cue appropriate maintenance regimens that include anti-TNFs and other steroid sparing agents while reducing protracted concomitant steroid use as intended by current quality measures.

\section{INTRODUCTION}

Inflammatory bowel disease (IBD) affects $\sim 1.4$ million people in the USA and costs $\$ 6.3$ billion annually, ${ }^{1}{ }^{2}$ with $35 \%$ of those

\section{Strengths and limitations of this study}

- A nationally representative sample of US adults aged $\geq 65$ years, with inflammatory bowel disease (IBD).

- Large cohort $(n=8502)$ allowing the study of drug utilisation in the understudied cohort of older Americans with IBD.

- Data restrictions were associated with the use of claims data, which required surrogate marker use for IBD severity and limited ascertainment of competing reasons for steroid utilisation.

- We may have underestimated reported use of self-administered drug therapy in some dual Medicare and Medicaid eligible recipients because we did not have access to Medicaid prescription files. However, $90 \%$ of antitumour necrosis factor utilisation would be captured by Medicare claims because facility-administered infliximab was the primary agent used.

costs attributed to drug therapy. ${ }^{2}$ Treatment of IBD aims to achieve remission and to decrease hospitalisations, surgeries and chronic steroid use while improving quality of life. ${ }^{3-6}$ Reducing maintenance steroid use is important given the complications of chronic steroids and their inability to maintain disease remission. ${ }^{5} 7$ Tumour necrosis factor (TNF) antagonists (anti-TNFs) reduce both disease activity and steroid requirements in moderate to severe IBD, thus justifying the utilisation of these costly drugs. ${ }^{3} 89$ The Center for Medicare and Medicaid Services (CMS) is the administrator for Medicare, a universal health insurance programme for US citizens $\geq 65$ years old. It provides insurance through a fee for service mechanism for approximately $88 \%$ of all beneficiaries, the majority of whom also enrol in the Medicare part D prescription drug benefit. ${ }^{10}{ }^{11}$ However, a small proportion of indigent older individuals may also 
receive Medicaid coverage. Medicaid insurance is administered by individual US state governments according to state and federal government guidelines. Medicaid recipients may receive full Medicaid benefits (which include prescription drug coverage) or may only receive assistance with their Medicare co-insurance payments. ${ }^{12}$ Given the coverage provided by Medicare, CMS recently adopted IBD-specific quality measures targeting drug therapy optimisation that will impact the care of most US citizens $\geq 65$ years old. ${ }^{13}$ These measures call for the use of steroid-sparing regimens, highlighting the importance of anti-TNF utilisation.

Despite strong evidence supporting anti-TNFs to maintain steroid-free remission and the rising prevalence of IBD in older patients, there are few studies examining the use of anti-TNF agents in older adults. ${ }^{14} 15$ The limited data available suggest that these treatments are infrequently used in patients 65 years and older with IBD. One study of a regional hospital system examined drug use in older adults $(\mathrm{n}=393)$, and showed higher use of maintenance steroids $(n=124)$ than of anti-TNFs and other steroid-sparing immunomodulators combined $(\mathrm{n}=37) .{ }^{15}$ Only $2.6 \%$ of older adults were receiving anti-TNFs whereas $>30 \%$ were receiving steroids. An Italian study found that only 95 of the 3079 (3.1\%) anti-TNF recipients in their healthcare system were $\geq 65$ years old. ${ }^{14}$

The drivers of low anti-TNF utilisation in older patients are likely several, including the exclusion of older adults from anti-TNF clinical trials, potentially less active or symptomatic disease in some older patients, colectomies in some patients with ulcerative colitis and the perceived risk of anti-TNF adverse events occurring with greater frequency in older individuals. ${ }^{16-19}$

We hypothesised a quality gap whereby older adults infrequently receive anti-TNF treatment. Furthermore, concerns about the risks of potent immunosuppressive agents would exacerbate underuse in the oldest subset of older patients and in those with a lower general state of health. The objectives of the current study are to quantify the prevalence and predictors of anti-TNF use, and to describe steroid use in a nationally representative US sample of patients $\geq 65$ years with IBD, immediately prior to quality measure publication. Our analysis illustrates baseline drug utilisation experience, serves as a reference for future studies of the impact of quality measures and provides a potential roadmap for how these quality measures may need to evolve to optimise the care of older patients with IBD.

\section{METHODS}

\section{Study design, data source and sample description}

We conducted a retrospective cohort study of a random sample of Medicare Fee for Service patients aged $\geq 65$ years, with at least 12 months of parts $\mathrm{A}$ and $\mathrm{B}$, and 6 months of part D coverage, during the years 2006-2009. Data were included for up to 6 months prior to coverage by Medicare $\mathrm{D}$. The first 12 months of data are referred to as collected during the 'baseline year' and data collected thereafter as being from the 'follow-up period'.

Claims and administrative data for the Medicare beneficiaries were merged with Census 2010 Summary File 3 (SF3) data (yielding socioeconomic characteristics of household locations). Study participants had a diagnosis of IBD identified by at least two claims for an appropriate International Classification of Diseases, Ninth Edition (ICD-9) code ( $\geq 2$ claims for either (CD:555.xx) or (UC:556.xx)), according to a case-finding algorithm that confirmed $\sim 86 \%$ of cases on chart review, with a specificity of $79 \% .^{20}$ Participants with contraindications to anti-TNF therapy (advanced congestive heart failure (CHF), malignancy) were excluded (see online supplementary appendix 1). All patients meeting criteria were included in the study, which provided an adequate number of events to evaluate predictors of new anti-TNF use (using the guideline of 1 predictor for every 10 events). Advanced CHF was defined as a diagnosis of CHF and at least one CHF hospitalisation during the baseline year. ${ }^{21}$ Malignancies were identified using the 2008 Elixhauser criteria, V.3.3 via ICD-9 codes (see online supplementary appendix 1 ). In accordance with the London position statement on biological therapy, infections were not considered contraindications for the purpose of study exclusion because even patients with latent infections can re-enter the anti-TNF eligible treatment pool following antimicrobial therapy and infection eradication or suppression. ${ }^{22}$

\section{Outcome variables}

The outcome variable was new episodes of anti-TNF utilisation (patients that began a course of anti-TNF therapy during the follow-up period). Prevalent anti-TNF use, defined as use that occurred during the baseline period, was described, but not used as an outcome in regression analysis because explanatory variables were determined while patients were already receiving anti-TNFs. The self-injectable anti-TNF agent (adalimumab) was ascertained from Medicare part D prescription events using the Cerner Multum database (Cerner Multum Incorporated, Denver, Colorado, USA). Infliximab administered through home infusion was found in Medicare part $\mathrm{D}$ claims, ${ }^{23}$ and facility-administered infliximab was identified on inpatient and outpatient facility claims submitted for Healthcare Common Procedure Coding System (HCPCS) J-code $1745 .^{24}$ The vast majority of patients receiving anti-TNF therapy during the time frame of the study would have the agent administered in a healthcare facility. Since our study utilises claims data, we are assured that a claim was filed because patients came into the facility and received therapy.

\section{Explanatory variables}

Predictors of anti-TNF use were determined during the baseline year, and included use of IBD drug classes. The 
use of oral steroids was determined across the duration of part D coverage, and categorised as a three-level variable according to treatment duration by constructing a patient day data set with patients assigned to having received therapy on a given day based on the ReComp algorithm $^{25}$ and assuming medication adherence: non-users, short-term users $(<180$ consecutive days $)$ or maintenance users with $\geq 180$ consecutive days of steroids with no more than a 5-day gap in treatment. ${ }^{13} 26$ Steroid doses and dosing regimens were not considered in this definition since substantial insult has been demonstrated through cumulative steroid exposures resulting from doses as low as $5 \mathrm{mg}$ daily prednisone equivalent, if used for greater than 3 months. ${ }^{27}$ Baseline oral steroid use was used in the regression analysis.

IBD severity was accounted for by including indicator variables for IBD-related surgery and $>1$ endoscopic procedure (see online supplementary appendix 1). ${ }^{28} 29$ IBD patients with higher colorectal cancer risk should have 1 surveillance endoscopy annually; ${ }^{30}$ thus, $>1$ endoscopic procedure during the baseline year was considered to indicate more severe disease.

Several covariates were included to characterise the participant's baseline health status. Specifically, Charlson Comorbidity Index and polypharmacy ( $\geq 5$ drugs $)^{31} 32$ were considered as well as variables indicating that there was a hospitalisation and whether a gastroenterologist was seen for an E\&M visit appropriate for an IBD encounter. ${ }^{33}$ Finally, sociodemographic variables identifying urban residential status through rural urban commuting area codes, ${ }^{34}$ region and socioeconomic status (Medicaid coverage status), were considered.

\section{Statistical analysis}

Descriptive statistics are presented for the entire cohort. Prevalent baseline users were excluded from models evaluating the relationship between new episodes of anti-TNF utilisation and patient characteristics. We used Poisson multivariable regression with a $\log$ link and robust SEs. As the cohort was dynamic, with varying patient follow-up times, a time-offset was used to adjust for longer observation time, allows participants greater time to initiate drug therapy. Results are presented as incidence rate ratios and 95\% CIs. Step-wise model building was employed with age, sex, region, urban status and IBD drug class included in the initial model, and all additional covariates with marginal statistical significance $(p<0.1)$ were retained in the final model.

Statistical analysis was conducted using Stata V.13 (StataCorp, College Station, Texas, USA).

\section{RESULTS}

Eighty-two per cent of the full IBD cohort $(n=10362)$ were without anti-TNF contraindications and, therefore, eligible for study ( $n=8502$; table 1$)$.

All 8502 patients were included in the descriptive analysis. Prevalent anti-TNF users were excluded from the multivariable regression analysis of new anti-TNF utilisation because the analysis was conducted to establish predictors of new anti-TNF use during the follow-up period $(\mathrm{n}=8307$; figure 1 ).

Approximately half of all patients and $63 \%$ of new anti-TNF users visited a gastroenterologist during the baseline period. Sixty-seven per cent of new anti-TNF users were aged 75 years or younger, $96 \%$ were $<85$ years old and no patient $>90$ years old received anti-TNF therapy (cohort age range $65-104$ ). Notably, $22 \%$ of the full cohort and $>40 \%$ of new anti-TNF users received a course of steroids during the baseline period (table 2). New anti-TNF recipients also had higher non-biological immunomodulator utilisation rates at baseline than did anti-TNF non-users.

Overall, 3.7\% $(\mathrm{n}=316)$ of the cohort received anti-TNF therapy during the course of the study $(1.4 \%$ new episode use and 2.3\% baseline prevalent use; $85.5 \%$ infliximab, $10.1 \%$ adalimumab, and $4.4 \%$ had both infliximab and adalimumab over the study course). The median follow-up period among participants was 2.4 years.

Importantly, 61 of the 316 anti-TNF recipients (19\%) received steroid courses lasting greater than 3 months and $10 \%$ received a maintenance course that was 6 months or greater while on anti-TNF therapy during the observation period (baseline and follow-up periods combined). Among concomitant anti-TNF and steroid users, $43 \%$ had multiple steroid courses spanning $>3$ months while receiving anti-TNFs.

\section{Multivariable analyses of predictors of anti-TNF utilisation}

New anti-TNF users $(n=121)$ were relatively younger than non-users, statistically less likely to be enrolled in Medicaid, and more likely to receive other classes of IBD agents and have a hospitalisation in the baseline year (table 3$)$.

\section{Sensitivity analyses}

Since some study participants may not have had IBD severity requiring anti-TNF initiation, a sensitivity analysis was conducted restricting the sample to patients who received IBD drugs at baseline $(n=4397)$; findings were similar. Sensitivity analyses were also conducted to evaluate the impact of missing values of urban status $(\mathrm{n}=60)$. Excluding this variable from the final model, we compared coefficients with and without individuals with missing values. We found little difference between the two models.

\section{DISCUSSION}

Compared with reported rates in younger populations, we found low, $3.7 \%$, utilisation of anti-TNFs in older patients. The rate of utilisation, however, was comparable to rates found in other studies of patients aged $\geq 65$ years with IBD $(\sim 3 \%) .{ }^{14}{ }^{15}$ While older patients may suffer from less severe disease activity, ${ }^{19}$ we still 
Table 1 Participant baseline characteristics, overall and anti-TNF utilisation status

\begin{tabular}{|c|c|c|c|c|c|c|}
\hline & \multicolumn{2}{|c|}{$\begin{array}{l}\text { Full sample } \\
(n=8502)\end{array}$} & \multicolumn{2}{|c|}{$\begin{array}{l}\text { anti-TNF non-users } \\
(\mathrm{n}=\mathbf{8 1 8 6})\end{array}$} & \multicolumn{2}{|c|}{$\begin{array}{l}\text { New episode of } \\
\text { anti-TNF users } \\
(n=121)^{\star}\end{array}$} \\
\hline & (n) & (\%) & (n) & (\%) & (n) & $(\%)$ \\
\hline Age mean (SD) & & $76(8)$ & & $76(8)$ & & $73(6)$ \\
\hline Female & 6111 & 72 & 5891 & 72 & 83 & 69 \\
\hline Caucasian & 7708 & 91 & 7408 & 91 & 118 & $98 \dagger$ \\
\hline \multicolumn{7}{|l|}{ Region } \\
\hline Northeast & 2104 & 25 & 2044 & 25 & 29 & 24 \\
\hline Southeast & 2385 & 28 & 2278 & 28 & 40 & 33 \\
\hline Midwest & 2004 & 24 & 1922 & 24 & 28 & 23 \\
\hline Rocky Mountains & 239 & 3 & 234 & 3 & $<11 \dagger$ & - \\
\hline Southwest & 802 & 9 & 768 & 9 & 12 & 10 \\
\hline Pacific $\ddagger$ & 968 & 11 & 940 & 12 & $<11 \dagger$ & - \\
\hline Urban/suburban & 6426 & 76 & 6192 & 76 & 87 & 72 \\
\hline Medicaid coverage & 1915 & 23 & 1885 & 23 & $<11 \dagger$ & - \\
\hline Polypharmacy ( $\geq 5$ drugs) & 4920 & 62 & 4719 & 62 & 72 & 60 \\
\hline Charlson Index Mean (SD) & & $1(2)$ & & $1(2)$ & & $1(2)$ \\
\hline Gastroenterologist visit & 4392 & 52 & 4158 & 51 & 76 & 63 \\
\hline$>1$ endoscopy & 1183 & 14 & 1141 & 14 & 20 & 17 \\
\hline IBD surgery & 211 & 3 & 199 & 2 & $<11 \dagger$ & - \\
\hline Hospitalisations mean (SD) & & $1(1)$ & & $1(1)$ & & $1(1)$ \\
\hline
\end{tabular}

found anti-TNF utilisation rates in the current study to be low compared with estimates of $11 \%$ in the general IBD population. ${ }^{14} 1535$ We found the lowest utilisation among the oldest patients, with two-thirds of anti-TNF utilisation reserved for patients aged $\leq 75$ years. Our study had several strengths, including examination of a nationally representative sample of US adults aged 65 years or older with IBD. Despite rising IBD prevalence in this growing population, few studies have examined patients' anti-TNF utilisation. ${ }^{14}{ }^{15}$ Previous studies were conducted in geographically restricted or non-US populations. Using a national Medicare sample, we were
Figure 1 Study participation (IBD, inflammatory bowel disease; TNF, tumour necrosis factor). *Case-finding algorithm criteria are met with $\geq 2$ claims for CD:555.xx or UC:556.xx.

${ }^{* * *}$ Anti-TNF contraindications are advanced $\mathrm{CHF}$ and malignancies as defined in online supplementary appendix 1 .

***Prevalent anti-TNF users were already receiving therapy during the baseline period.

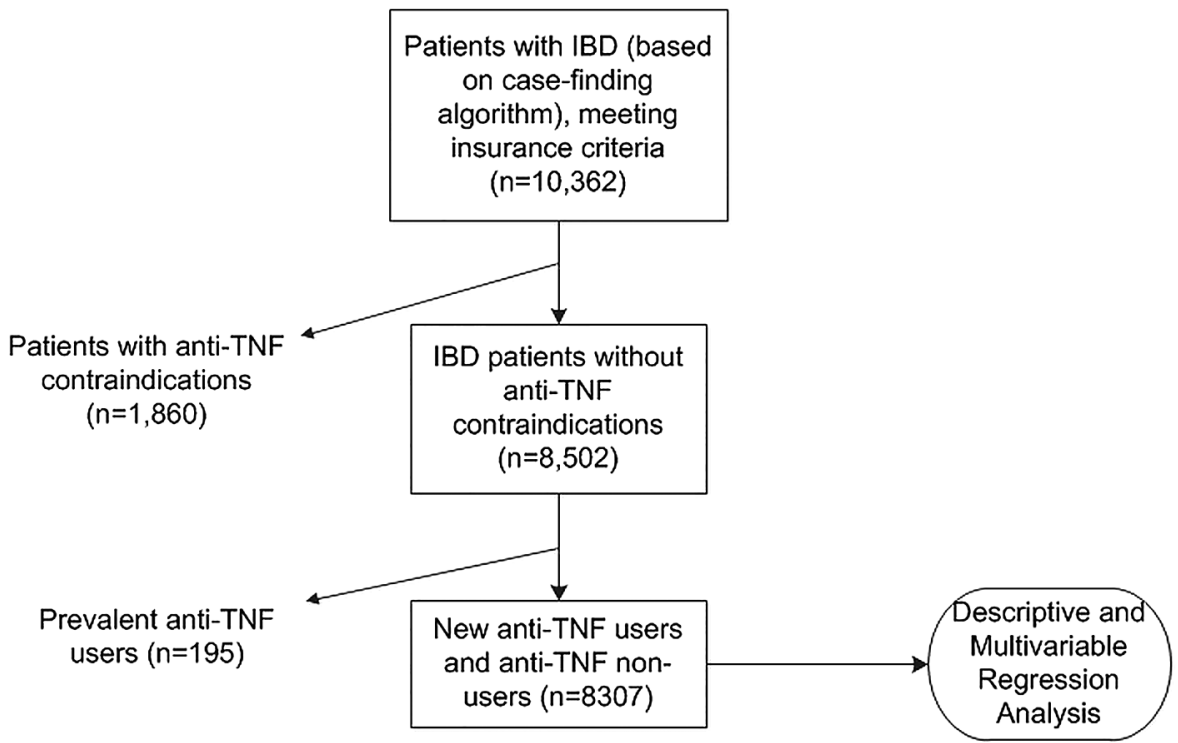


Table 2 Baseline IBD drug class utilisation by non-anti-TNF baseline users

\begin{tabular}{|c|c|c|c|c|c|}
\hline & \multicolumn{2}{|c|}{$\begin{array}{l}\text { anti-TNF non-users } \\
(\mathrm{n}=8186)\end{array}$} & \multicolumn{3}{|c|}{ New anti-TNF users $(n=121)$} \\
\hline & $\mathbf{n}$ & Per cent & $\mathbf{N}$ & Per cent & p Value ${ }^{\star}$ \\
\hline \multicolumn{5}{|l|}{ Systemic corticosteroids (oral) } & $<0.01$ \\
\hline Short course & 1486 & 18 & 49 & 40 & \\
\hline Maintenance therapy & 216 & 3 & $<11 \dagger$ & $\dagger$ & \\
\hline Non-biological immunomodulators & 378 & 5 & 26 & 22 & $<0.01$ \\
\hline Aminosalicylates & 2858 & 35 & 73 & 60 & $<0.01$ \\
\hline Locally administered steroids & 97 & 1 & $<11 \dagger$ & $\dagger$ & $<0.01$ \\
\hline Antidiarrhoeals & 733 & 9.0 & $<11 \dagger$ & $\dagger$ & 0.56 \\
\hline \multicolumn{6}{|c|}{$\begin{array}{l}\text { New anti-TNF utilisers initiated therapy after the completion of the baseline period. } \\
\text { Prevalent anti-TNF utilisers were already receiving therapy during the baseline study period }(n=195) \text { and were excluded from this analysis. } \\
\text { *Bivariate analyses is the comparison of new episodes of use to non-use }(n=8307) \text {. } \\
\text { tCell size is too small and requires suppression as part of the data use agreement. } \\
\text { IBD, inflammatory bowel disease; TNF, tumour necrosis factor. }\end{array}$} \\
\hline
\end{tabular}

able to include 8502 patients with IBD, allowing the identification of anti-TNF use and its predictors, and appraisal of concomitant maintenance steroid use.

The underuse of anti-TNFs in older adults may be due to major anti-TNF clinical trials largely excluding patients aged $\geq 65$ years, resulting in median study population ages of $34-36$ years. ${ }^{16}$ Hence, acceptable safety profiles and outcomes (decreased surgeries and hospitalisations) have not been demonstrated in this subgroup of patients. Moreover, infection and malignancy adverse

Table 3 Multivariable rate ratios and $95 \%$ Cls predicting new episodes ( $n-121)$ of anti-TNF use

\begin{tabular}{|c|c|c|}
\hline & IRR $^{*}$ & Cl \\
\hline \multirow[t]{2}{*}{ Age (5 years) } & 0.77 & (0.68 to 0.88$)$ \\
\hline & 1.04 & (0.71 to 1.54$)$ \\
\hline Medicaid coverage & 0.34 & (0.18 to 0.66$)$ \\
\hline \multicolumn{3}{|l|}{ Region } \\
\hline Midwest & 1.00 & (Reference) \\
\hline Northeast & 1.17 & (0.69 to 1.97$)$ \\
\hline Southeast & 1.29 & (0.80 to 2.07$)$ \\
\hline Southwest & 1.13 & (0.57 to 2.22$)$ \\
\hline Rocky Mountains & 0.61 & (0.14 to 2.63$)$ \\
\hline Pacific and $\mathrm{HI}, \mathrm{AK}, \mathrm{PR}$ & 0.99 & (0.49 to 2.01$)$ \\
\hline Urban/suburban & 0.89 & (0.60 to 1.34$)$ \\
\hline \multicolumn{3}{|l|}{ Systemic corticosteroids (oral) } \\
\hline Short course & 2.35 & (1.59 to 3.47$)$ \\
\hline Maintenance therapy & 2.40 & (1.05 to 5.48$)$ \\
\hline Non-biological immunomodulators & 3.35 & (2.10 to 5.35$)$ \\
\hline Aminosalicylates & 2.03 & (1.37 to 3.02$)$ \\
\hline Locally administered steroids & 3.80 & (1.90 to 7.61$)$ \\
\hline Antidiarrhoeals & 0.67 & (0.33 to 1.33$)$ \\
\hline Hospitalisations & 1.18 & (1.01 to 1.38$)$ \\
\hline Endoscopy (>1) & 0.97 & (0.43 to 2.23$)$ \\
\hline IBD-associated surgery & 1.09 & (0.14 to 8.52$)$ \\
\hline
\end{tabular}

${ }^{*}$ Poisson regression with time-to-event as time offset, incident anti-TNF use as dependent variable.

AK, Alaska; HI, Hawaii; IBD, inflammatory bowel disease; IRR, incidence rate ratios; PR, Puerto Rico; TNF, tumour necrosis factor. events may be major concerns for anti-TNF use in older patients. ${ }^{17}$

Infection and malignancy risks are widely discussed in the anti-TNF literature. ${ }^{36}$ A systematic review noted that the infection risk exclusively attributable to anti-TNFs is difficult to estimate due to other concomitant immunosuppressive therapies, but reported low overall risk of serious infection in anti-TNF users, particularly with screening and vaccination prior to anti-TNF initiation. ${ }^{36}$ Steroids, in contrast to anti-TNFs, show significantly higher infection risk. ${ }^{37}$ Malignancies, particularly lymphomas, might be more common in anti-TNF recipients, though the absolute risk is low and the role of anti-TNFs debatable. ${ }^{36}$ In summary, advanced age, comorbidities and the lack of research with these drugs in the older population likely contributed to low anti-TNF use, yet older adults remain an important target population for reducing steroid usage through steroid-sparing therapies, including anti-TNFs.

We observed that older adults with dual Medicare and Medicaid coverage had lower anti-TNF utilisation. This finding was not anticipated since Medicare beneficiaries with Medicaid coverage have greatly reduced cost-sharing for medical visits (infused anti-TNF administration) and prescription drug co-payments (self-administered anti-TNFs), and the ability of reduced cost-sharing to increase biological use and drive anti-TNF selection is well documented. ${ }^{38}{ }^{39}$ However, infliximab represented $90 \%$ of anti-TNF use over the course of this study, and requires the time and expense of commuting to a healthcare facility to receive the drug. Therefore, lower anti-TNF use among individuals who had Medicaid may reflect logistical barriers, patient preferences or other provider and system factors.

A large proportion of patients received concurrent maintenance steroids and anti-TNF therapy during the study, which was surprising. While burst steroids may be used to induce remission during anti-TNF initiation or regimen adjustments, maintenance steroids are not guideline supported. However, there is lack of consensus 
regarding optimal anti-TNF monitoring, titration, co-therapy use and drug cessation. Anti-TNF nonresponse (intentional steroid use) or clinical inertia (unintended prolonged steroid use without discontinuation) are both plausible explanations for our finding. ${ }^{40}$ As many as 50\% of anti-TNF recipients may become secondary non-responders (lose treatment response following a documented therapeutic response) after 1 year of therapy, ${ }^{40}$ so it is possible that some patients lost response to treatment. A loss of response should result in anti-TNF dose/interval adjustment, switching anti-TNF agents, anti-TNF discontinuation or the addition of a non-biological immunomodulator to the anti-TNF regimen, but could lead to steroid use. ${ }^{40}$ Conversely, patients and providers may be conditioned to expect steroid use and overlook steroid tapering.

A policy approach to reduce unintended protracted concomitant steroid and anti-TNF utilisation could include expansion of CMS quality measures to explicitly require documented steroid taper plans for patients on maintenance steroid regimens analogous to the rheumatoid arthritis quality measure calling for annual taper plan documentation (Rheumatoid Arthritis CMS Physician Quality Reporting System (PQRS) Measure \#180). ${ }^{42}$ Broadly speaking, decreasing steroid use may have multiple positive impacts. Patients who are no longer responding to anti-TNF or other steroid-sparing therapy may have their primary therapies more closely monitored and better titrated to treatment response instead of having steroids added to their regimen or steroid therapy prolonged to manage disease flares. Additionally, patients may avoid steroid-associated adverse events that are aggravated when combined with other immunomodulators. While exclusively implementing quality measures or, in this case, expanding quality measures to include steroid taper plans, may not result in substantive behaviour change, there is evidence that quality measure enforcement with an incentive/penalty structure and public reporting of outcomes may positively impact the quality of care received by affected patients. ${ }^{4-45}$ Both of these strategies, payment adjustments and public reporting, are underway with the CMS measures and PQRS.

In addition to a policy approach, a pragmatic strategy to decrease steroid overuse in this population, engaging patients and primary care clinicians in efforts to understand and promote steroid tapering goals, could also be pursued. Given the fact that only $52 \%$ of patients in the current study were seen by a gastroenterologist during the baseline year, it is important that primary care clinicians are empowered to verify the frequency and duration of steroid use with patients, as they may be the provider executing or managing the IBD care plan for long periods of time between gastroenterologist visits. It is also pivotal that patients are fully aware of the safety concerns associated with steroids and report courses of steroid therapy prescribed by all co-managing providers to their primary care clinician, so that they can also advocate for limited steroid use.
Despite strengths of cohort size and representatives, this study had some limitations. A disease-prevalent cohort was used, and disease duration and severity are difficult to ascertain in claims data. Recognising that the majority of patients are diagnosed in the second and third decades of life, we expect that $85-90 \%$ of patients had long-standing disease comprising a homogeneous sample with respect to disease duration. With claims data, we did not have access to symptom history, biomarker values or endoscopy results, and we could not assign steroid use to a particular disease state, as it has widespread use among many disease states and older patients are typically comorbid. Given this data restriction, we used surrogate markers ( $>1$ endoscopy and IBD-associated surgeries during the baseline year) to characterise IBD severity and activity, but given the expansive list of steroid indications, we were unable to account for competing uses and acknowledge that some steroid utilisation may be misclassified in this analysis. However, a report derived from National Health and Nutrition Examination Survey (NHANES) III data showed that approximately $1.7 \%$ of US citizens aged $\geq 60$ years receive glucocorticoids. ${ }^{46}$ This rate is far lower than for those observed in the current study. An additional limitation of our database is that it contains claims for older patients and, as such, we cannot make direct comparisons to drug utilisation in younger patients with IBD. Finally, we may have underestimated the use of part D reimbursed agents paid by Medicaid. Nonetheless, a sensitivity analysis excluding patients without IBD drug claims showed similar results to the main analysis. Overall, strengths of this large nationally representative cohort offer a baseline portrayal of anti-TNF and steroid utilisation for future assessments of the impact of the quality measures on prescribing.

In conclusion, our findings point to important potential quality gaps including anti-TNF underuse, aggravated by higher age, and substantial steroid use in older adults during the observed period. Our study highlights the need for a follow-up assessment of drug utilisation following the full adoption of the CMS quality measures, the pragmatic clinical need to reduce steroid overuse in older adults, which may require engaging patients and primary care providers. Moreover, the findings suggest that modifying national quality measures to explicitly call for documented steroid taper plans may be necessary to simultaneously increase the use of steroid-sparing maintenance regimens and reduce concomitant steroid use.

\section{Author affiliations}

${ }^{1}$ Pharmaceutical Health Services Research Department, University of Maryland School of Pharmacy, Baltimore, Maryland, USA

${ }^{2}$ Department of Medicine, Rheumatology Division, University of Wisconsin School of Medicine and Public Health, Madison, Wisconsin, USA

${ }^{3}$ Department of Population Health Sciences, University of Wisconsin School of Medicine and Public Health, Madison, Wisconsin, USA

${ }^{4}$ Department of Biostatistics \& Medical Informatics, University of Wisconsin School of Medicine and Public Health, Madison, Wisconsin, USA 
${ }^{5}$ Center for Health Equity Research and Promotion, Veterans Affairs Pittsburgh Medical Center, Pittsburgh, Pennsylvania, USA

${ }^{6}$ Department of Pharmacy and Therapeutics, University of Pittsburgh School of Pharmacy, Pittsburgh, Pennsylvania, USA

${ }^{7}$ Department of Medicine, Division of Gastroenterology and Hepatology, University of Wisconsin School of Medicine and Public Health, Madison, Wisconsin, USA

${ }^{8}$ Department of Family Medicine, University of Wisconsin School of Medicine and Public Health, Madison, Wisconsin, USA

${ }^{9}$ Department of Surgery, University of Wisconsin School of Medicine and Public Health, Madison, Wisconsin, USA

Contributors SLJ conceived and designed the study, conducted the analyses, data interpretation and manuscript production. SLJ, CMB, MP, CTT, JMW and MAS approved the final submitted manuscript. CMB participated in study design, data interpretation and manuscript writing and editing. MP participated in study and analytic method design, data analysis, data interpretation and manuscript writing. CTT and JMW participated in data interpretation, and manuscript writing and editing. MAS participated in study conception, data interpretation and manuscript production.

Funding This work was supported by the Agency for Healthcare Research and Quality [grant number 1 F32 HSO22786-01].

Competing interests None declared.

Ethics approval University of Wisconsin Institutional Review Board

Provenance and peer review Not commissioned; externally peer reviewed.

Data sharing statement No additional data are available.

Open Access This is an Open Access article distributed in accordance with the Creative Commons Attribution Non Commercial (CC BY-NC 4.0) license, which permits others to distribute, remix, adapt, build upon this work noncommercially, and license their derivative works on different terms, provided the original work is properly cited and the use is non-commercial. See: http:// creativecommons.org/licenses/by-nc/4.0/

\section{REFERENCES}

1. Park K, Bass D. Inflammatory bowel disease-attributable costs and cost-effective strategies in the United States: a review. Inflamm Bowel Dis 2011;17:1603-9.

2. Kappelman M, Rifas-Shiman S, Porter C, et al. Direct health care costs of Crohn's disease and ulcerative colitis in US children and adults. Gastroenterology 2008;135:1907-13.

3. Feagan B, Lemann M, Befrits R, et al. Recommendations for the treatment of Crohn's disease with tumor necrosis factor antagonists: an expert consensus report. Inflamm Bowel Dis 2012;18:152-60.

4. Sherman M, Tsynman D, Kim A, et al. Sustained improvement in health-related quality of life measures in patients with inflammatory bowel disease receiving prolonged anti-tumor necrosis factor therapy. J Dig Dis 2014;15:174-9.

5. van Assche G, Vermeire S, Rutgeerts P. Mucosal healing and anti TNFs in IBD. Curr Drug Targets 2010;11:227-33.

6. Allen P, Peyrin-Biroulet L. Moving towards disease modification in inflammatory bowel disease therapy. Curr Opin Gastroenterol 2013;29:397-404.

7. Curkovic I, Egbring M, Kullak-Ublick G. Risks of inflammatory bowe disease treatment with glucocorticosteroids and aminosalicylates. Dig Dis 2013;31:368-73.

8. Lichtenstein GR, Yan S, Bala M, et al. Infliximab maintenance treatment reduces hospitalizations, surgeries, and procedures in fistulizing Crohn's disease. Gastroenterology 2005;128:862-9.

9. Rubenstein J, Chong R, Cohen R. Infliximab decreases resource use among patients with Crohn's disease. J Clin Gastroenterol 2002;35:151-6.

10. Foote SB, Halaas GW. Defining a future for fee-for-service Medicare. Health Aff 2006;25:864-8.

11. Szrek S, Bundorf MK. Enrollment in prescription drug insurance: the interaction of numeracy and choice set size. Health Psychol 2014:33:340-8.

12. Centers for Medicaid and Medicare Services. Dual eligible beneficiaries under the Medicare and Medicaid Programs. 2014 http://www.cms.gov/Outreach-and Education/MedicareLearning-Network-MLN/MLNProducts/downloads/Medicare_
Beneficiaries_Dual_Eligibles_At_a_Glance.pdf (accessed 23 Jul 2015)

13. Centers for Medicare and Medicaid Services. 2011 Physician Quality Reporting System, 2011. http://www.cms.gov/Medicare/QualityInitiatives-Patient-Assessment-Instruments/PQRS/2011 Physician-Quality-Reporting-System.html (accessed 4 Apr 2013).

14. Cottone $\mathrm{M}$, Kohn A, Daperno $\mathrm{M}$, et al. Advanced age is an independent risk factor for severe infections and mortality in patients given anti-tumor necrosis factor therapy for inflammatory bowel disease. Clin Gastroenterol Hepatol 2011;9:30-5.

15. Juneja M, Baidoo L, Schwartz $M$, et al. Geriatric inflammatory bowel disease: phenotypic presentation, treatment patterns, nutritional status, outcomes, and comorbidity. Dig Dis Sci 2012;57:2408-15.

16. Ha C, Ullman T, Siegel C, et al. Patients enrolled in randomized controlled trials do not represent the inflammatory bowel disease patient population. Clin Gastroenterol Hepatol 2012;10:1002-7.

17. Katz S, Pardi D. Inflammatory bowel disease of the elderly: frequently asked questions (FAQs). Am J Gastroenterol 2011;106:1889-97.

18. Pardi D, Loftus E, Camilleri M. Treatment of inflammatory bowel disease in the elderly. Drugs Aging 2002;19:355-63.

19. Picco M, Cangemi J. Inflammatory bowel disease in the elderly. Gastroenterol Clin N Am 2009;38:447-62.

20. Liu L, Allison J, Herrinton L. Validity of computerized diagnoses, procedures, and drugs for inflammatory bowel disease in northern California managed care organization. Pharmacoepidemiol Drug Saf 2009;18:1086-93.

21. Joynt K, Orav E, Jha A. The association between hospital volume and processes, outcomes, and costs of care for congestive heart failure. Ann Intern Med 2011;154:94-102.

22. D'Haens G, Panaccione R, Higgins P, et al. The London Position Statement of the World Congress of Gastroenterology on Biological Therapy for IBD with the European Crohn's and Colitis Organization: when to start, when to stop, which drug to choose, and how to predict response? Am J Gastroenterol 2011;106:199-212.

23. MEDPac. Report to the Congress: Medicare and the Health Care Delivery System. 2012. http://www.medpac.gov/chapters/Jun12 Ch06 APPENDIX.pdf (accessed 4 Apr 2013).

24. Centers for Medicare and Medicaid Services. Medicare claims processing manual, chapter 17: drugs and biologicals. Baltimore, MD: Centers for Medicare \& Medicaid Services, 2012

25. Bryson $C, A u D$, Young B, et al. A refill adherence algorithm for multiple short intervals to estimate refill compliance (ReComp). Med Care 2007; 45:497-504.

26. Curtis J, Westfall A, Allison J, et al. Longitudinal patterns in the prevention of osteoporosis in glucocorticoid-treated patients. Arthritis Rheum 2005;52:2485-94.

27. Feldstein AC, Elmer PJ, Nichols GA, et al. Practice patterns in patients at risk for glucocorticoid-induced osteoporosis. Osteoporosis Int 2005;16:2168-74

28. Bewtra M, Su C, Lewis J. Trends in hospitalization rates for inflammatory bowel disease in the United States. Clin Gastroenterol Hepatol 2007;5:597-601.

29. Herrinton L, Liu L, Weng X, et al. Role of thiopurine and anti-TNF therapy in lymphoma in inflammatory bowel disease. $A m \mathrm{~J}$ Gastroenterol 2011;106:2146-53.

30. Cairns S, Scholefield J, Steele R, et al. Guidelines for colorectal cancer screening and surveillance in moderate and high risk groups (update from 2002). Gut 2010;59:666-90.

31. Fincke B, Snyder K, Cantillon C, et al. Three complementary definitions of polypharmacy: methods, application and comparison of findings in a large prescription database. Pharmacoepidemiol Drug Saf 2005;14:121-8.

32. Charlson M, Pompei $\mathrm{P}$, Ales $\mathrm{K}$, et al. A new method of classifying prognostic comorbidity in longitudinal studies: development and validation. J Chronic Dis 1987;40:373-83.

33. American Gastroenterological Association Institute. IBD CPT codes ulcerative colitis \& Crohn's disease. Association TAG. http://www.gastro. org/practice/clinical-service-line/525-325PNQ_13-2_PDF_Document Updates CPT Codes- IBD Final.pdf (accessed 11 Apr 2014).

34. USDA Economic Research Service. Rural Urban Commuting Area Codes. 2005. http://www.ers.usda.gov/data-products/rural-urbancommuting-area-codes.aspx (accessed 4 Apr 2013).

35. vanDeen W, vanOijen M, Myers K, et al. A nationwide 2010-2012 analysis of U.S. health care utilizaiton in inflammatory bowel diseases. Inflamm Bowel Dis 2014;20:1747-53.

36. Targownik L, Bernstein C. Infectious and malignant complications of TNF inhibitor therapy in IBD. Am J Gastroenterol 2013;108:1835-42.

37. Zhang J, Xie F, Delzell E, et al. Association between vaccination for herpes zoster and risk of herpes zoster infection among older patients with selected immune-mediated diseases. J Am Med Assoc 2012;308:43-9. 
38. Yazdany J, Tonner C, Schmajuk G. Use and spending on biologic disease-modifying anti-rheumatic drugs for rheumatoid arthritis among US Medicare Beneficiaries. Arth Care Res 2015;67:1210-8.

39. Zhang J, Xie F, Delzell E, et al. Trends in the use of biologic agents among rheumatoid arthritis patients enrolled in the US Medicare program. Arthritis Care Res 2013;65:1743-51.

40. Allez M, Karmiris K, Louis E, et al. Report of the ECCO pathogenesis workshop on anti-TNF therapy failures in inflammatory bowel diseases: definitions, frequency and pharmacological aspects. J Crohns Colitis 2010;4:355-66.

41. O'Connor P, Sperl-Hillen J, Johnson P. Clinical inertia and outpatient errors. In: Battles J, Marks ES, Lewin DI, eds. Advances in patient safety: from research to implementation. Vol 2. Rockville, MD: Agency for Healthcare Research and Quality, 2005:293-9.
42. American College of Rheumatology. Physician Quality Reporting System (PQRS). 2011. http://www.rheumatology.org/practice/office/ pqri/index.asp (accessed 24 Dec 2014).

43. Koltov M, Damle NS. Health policy basics: physician quality reporting system. Ann Intern Med 2014;161:365-7.

44. Chatterjee $\mathrm{P}$, Joynt KE. Do cardiology quality measures actually improve patient outcomes? J Am Heart Assoc 2014;3:1-9.

45. Lamb G, Smith M, Weeks WB, et al. Publicly reported quality-of-care measures influenced Wisconsin physician groups to improve performance. Health Aff 2013;32:536-43.

46. Choi HK, Seeger JD. Glucocorticoid use and serum lipid levels in US adults: the third national health and nutrition examination survey. Arthritis Care Res 2005;53:528-35. 